\title{
The Potential of Rice Bran and Chito-Oligosaccharide as Natural Prebiotic on Traditional Tempe in Indonesia
}

\author{
Agnes Sri Harti, Anis Nurhidayati, and Desy Handayani
}

\begin{abstract}
Tempe is solid soybean product fermented with Rhizopus $s p$ mould which is widely consumed in Indonesia. Recently the concept of food fortification is used in characterizing health improvement food as functional bio-supplement. Chito-oligosaccharide rice bran tempe as one form of vegetable protein based fermented food fortification made of soybean. The mixture of soybean: rice bran (2:1) and chito-oligosaccharide $2 \%$ w/w shows optimum organoleptic result in rice bran chito-oligosaccharide tempe. Research results shows rice bran and chito-oligosaccharide is potential to be natural prebiotic in soybean fermentation namely tempe therefore it can be used as functional food that provides immunostimulatory effects.
\end{abstract}

Index Terms - Chito-oligosaccharides, prebiotic, rice bran, tempe.

\section{INTRODUCTION}

Tempe has been known as functional food made primarily of yellow soybean by fermentation process of Rhizopus $s p$ moulds as follows: Rhizopus oryzae, $R$. stolonifer, $R$. oligosporus [1]. Tempe is known as food favorable by all age while there are various products made of soybean. Because of its nutritional value, tempe is used worldwide in vegetarian cuisine, where it is used as a meat analogue. Prebiotics are non-digestible food ingredients that can provide benefits to the host effect therefore could stimulate colonic bacterial growth by increasing the number and activity of probiotics. Probiotic amount could be increased using prebiotics. Some classes of polysaccharide resistants, fiber, oligosaccharide, alcohol sugar, and chito-oligosaccharide are known as prebiotics [2]. Synbiotic bio-preparation in yoghurt gives synergistic effect as in vitro and in vivo cholesterol level degrader. Maltodextrin 2\%, fructo-oligosaccharide 2\% and its mixture $(1: 1)$ is able to supress the growth of pathogenic Escherichia coli [3].

Rice bran as by product of rice milling, obtained from outer layer of rice caryopsis, possesses bioactive component of oryzanol, tocopherol, ferulic acid that function to lower cholesterol and facillatate defecation. The hipocholesterolemic effects of rice bran and some of its fractions are very useful for health e.g. rice bran oil obviously lowers blood cholesterol rate, LDL, VLDL cholesterol, and increase HDL blood cholesterol rate; oryzanol and ability of unsaponified agent. Ferulic acid plays a role in lowering blood pressure and glucose in vivo. Oryzanol functions to

Manuscript received May 8, 2013; revised July 15, 2013.

Agnes Sri Harti, Anis Nurhidayati, and Desy Handayani are with the Kusuma Husada Surakarta Institute of Health Science of Surakarta Central Java Indonesia (e-mail: agnessriharti@yahoo.com). lower cholesterol and and increase production of erythromycin from culture of Saccharopolyspora erythraea ATCC 11635 [4].

Chitosan shows antibacterial, antimetastatic, antiurichemic and immunoadjuvant in vitro biocompatibility [5], [6]. Chitosan can absorb fat thus lowers cholesterol [7]-[10]. Chito- oligosaccharide (COS) obtained from chitosan derived of shrimp or crab waste potential and abundant in Indonesia as natural prebiotic source [11].

Traditionally, yellow soybean usually is used as main ingredients in tempe production in Indonesia. Dependence of imported soybean in tempe production causes high material price thus affects the production cost. The concept of food fortification is recently utilized for charaterization of health improvement food as functional bio-supplement food. Therefore various attempts need to be taken to substitute yellow soybean with other materials that are safe, nutritious and economics. Probiotic optimization can be done by selecting suitable strain; selecting substrates e.g. rice bran and chito-oligosaccharide. One new innovation that is potential to develop as chito-oligosaccharide rice bran tempe as natural healthy prebiotic food and bio-supplement that can provide immunostimulatory effects.

\section{MATERIAL AND METHODS}

\section{A. Rhizopus Sp Isolation and Rice Bran Synthesis}

Rhizopus sp inoculums in mould powder was inoculated in Sabaraud Glucose Agar media and incubated at room temperature. The identification Rhizopus sp was based on microscopic morphological examination.

\section{B. Synthesis of Chito-Oligosaccharice and Rice Bran}

The synthesis of chito-oligosaccharide from crab and shrimp shell waste used chitin deacetylation [12]-[20].

The synthesis of rice bran is obtained as by product milling of outer layer of rice caryopsis [21].

\section{Rice Bran Chito-Oligosaccharide Tempe Fermentation}

Soy bean is cleaned and soaked for 12-15 hours, husk is removed, followed by 15 minutes steaming and then set aside. Soy bean is added rice bran steamed at ratio 2: 1 and then set aside. The inoculated of $0.1 \%$ of Rhizopus sp inoculum into mixture rice bran and soybean, and chito-oligosaccharride $2 \% \mathrm{w} / \mathrm{w}$ then mixed throughly, wrapped in plastic or banana eaves and incubated in room temperature of $30^{\circ} \mathrm{C}$ for $24-36$ hours.

\section{Results Analysis}

Analyze of fermentation product covered protein, fat rate 
measurement and microbiological test. The organoleptic test used Hedonic method test against preference level (colour, smell, texture, flavour) by panelists.

\section{RESULTS AND DISCUSSION}

Isolation and identification of mould in inoculum powder was Rhizopus oligosporus.

TABLE I: ANALYZE OF PRODUCT FERMENTATION

\begin{tabular}{lllll}
\hline & $\begin{array}{l}\text { Level } \\
\text { protein } \\
(\% \mathrm{w} / \mathrm{w})\end{array}$ & $\begin{array}{l}\text { Level } \\
\text { fat } \\
(\% \mathrm{w} / \mathrm{w}\end{array}$ & E. coli & $\begin{array}{l}\text { Salmonell } \\
\mathrm{a}\end{array}$ \\
& & & & \\
& 1.83 & 4.80 & - & - \\
\hline $\begin{array}{l}\text { 1. Soy bean } \\
\text { 2. Rice bran }\end{array}$ & 0.99 & 1.58 & - & - \\
$\begin{array}{l}\text { Soy bean : rice bran }(2: 1) \\
\text { 3. with 2\% COS shrimp }\end{array}$ & 1.24 & 3.80 & - & - \\
shell & & & & - \\
$\begin{array}{l}\text { 4. with 2\% COS crab } \\
\text { shell }\end{array}$ & 1.31 & 4.26 & - & - \\
$\begin{array}{l}\text { 5. with 2\% chitosan } \\
\text { 6. with 2\% FOS }\end{array}$ & 1.07 & 4.24 & - & - \\
7. with 2\% Maltodextrin & 1.37 & 4.23 & - & - \\
\hline \hline
\end{tabular}

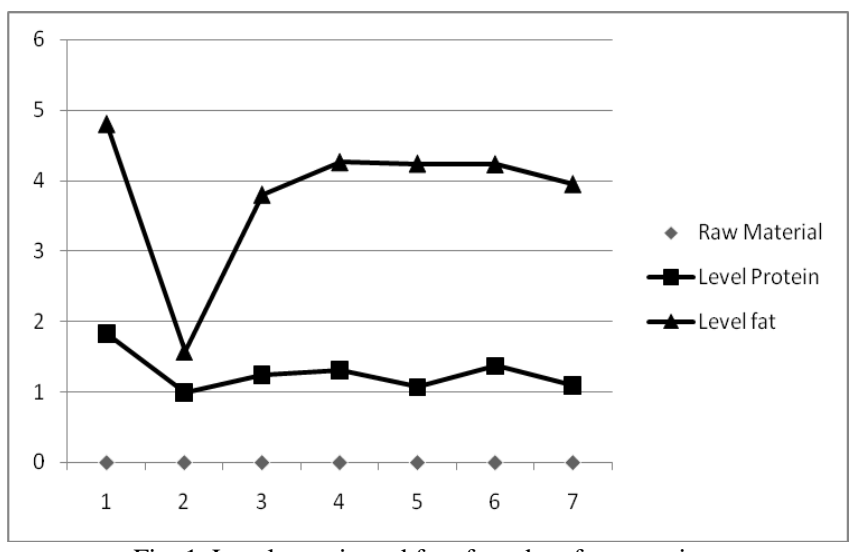

Fig. 1. Level protein and fat of product fermentation.

The research showed that rice bran chito-oligosaccharide is potential to be natural prebiotic in soybean fermentation or tempe. The mixture of soybean and rice bran giving the best organoleptic result is at ratio soybean and rice bran $=2: 1$. Utilization of soybeans mixed rice bran provides altenative to imported soybean dependence in Indonesia. Soybean and rice bran can be used by Rhizopus sp as its growth substrate. Rice bran with additional prebiotics $2 \%$ (chito-oligosaccharide, fructo- oligosaccharide or maltodextrin) show lower protein and fat rate compared to without prebiotic additional (see Table I). The fermentation process using soybean rice bran chito-oliogsaccharide improves digestibility value by reduction anti-nutrition factor as tannin and phytase in addition to production of acids which inhibit the production of pathogenic microbes and is particulary important in the manufacture of food designated for special targeted such as infants and aged ones. This show rice bran chito-oligosaccharide tempe fermentation process using Rhizopus sp inoculums can supply higher digestibility value since Rhizopus $s p$ secretes various extracellular enzymes e.g. protease, amylase, and lipase that hydrolyze macromolecule substrate in soybean and rice bran monomer or simpler compound that as a results is absorbed and synthesised in the body more easily [22], [23].

The soy carbohydrates in tempe become more digestible as a result of the fermentation process. The fermentation process also reduces the phytic acid in soy, which in turn allows the body to absorb the minerals that soy provides. The zygomycete Rhizopus oligosporus is traditionally used to ferment soybean tempe, but it is also possible to ferment other legumes and cereals to tempe. The traditional soybean tempe harbours a multitude of microorganisms with potentially beneficial or detrimental effects on quality. Lactic acid bacteria (LAB) have positive effects on the safety of soybean tempe, but the effects of LAB on R. oligosporus growth have not been investigated. Four LAB species, Lactobacillus plantarum, Lactobacillus fermentum, Lactobacillus reuteri and Lactococcus lactis were assessed for their growth abilities and their effects on R. oligosporus growth during barley tempe fermentation [24]

The organoleptic test on rice bran chito-oligosaccharide shows addition of rice bran and chito-oligosaccharide does not effect texture and smell, while preference level is subjective to rice bran fibre. This can be overcome by sieving rice bran more finely that better rice bran tempe texture is obtained.

\section{CONCLUSION}

Rice bran and chito-oligosaccharide function as natural prebiotics in traditional tempe in Indonesia and as functional food hence provides immunostimulatory effects.

\section{ACKNOWLEDGMENT}

The authors would like to thank the Directorate General of Higher Education Indonesia for supporting this research work under Fundamental grants 2013.

\section{REFERENCES}

[1] K. Kimura et al., "Crude rice bran diet decreases blood pressure in stroke-prone spontaneously hypertensive rats," Poster prensentation at the JSBBA 2005 Annual Meeting (Japan Society for Bioscience, Biotechnology, and Agrochemistry), Sapporo-Hokkaido, March 28-30, 2005.

[2] A. Bomba, R. Nemcova, S. Gancarcikova, R. Herich, P. Guba, and D. Mudronova, "Improvement of the probiotic their effect of microorganism by combination with maltodextrins, fructo-oligosaccharides and polyunsaturated fatty acid," British Journal of Nutrition, vol. 88, September 2002.

[3] H. J. Choi, J. Ahn, N. C. Kim, and H. S. Kwak, "The effects of microencapsulated chitooligosaccharide on physical and sensory properties of the milk," Asian-Australasian journal of animal sciences, vol. 19 , no. 9, pp. 1347-1353, 2006.

[4] D. T. Artini, "Sugar production and reduction of substrate rice bran by Rhizopus oryzae," Journal of Biotechnology, vol. 2, no. 1, 2005

[5] B. Dinesh, R. Bhakyaraj, and R. Vidhayalakshmi, "A low cost nutritious food 'Tempeh'," A Review. World Journal of Dairy \& Food Sciences, vol. 4, no. 1, pp. 22-27, 2009.

[6] A. S. Harti et al., "Biopreparation Chito-oligosaccharide (COS) of waste fishing experience as a source of prebiotics in functional food," Applied Research Report, Funded by the Central Java Provincial Education Department, 2010.

[7] A. S. Harti, "Biopreparation synbiotic (Probiotics and Prebiotics) in yoghurt as immunostimulants and lowering cholesterol," Research Report Competitive Research Grant Program based on National Priority Batch I, 2009. 
[8] A. S. Harti, "Synergistic effects assessment probiotics with prebiotics to diaregenic Escherichia coli.," Young Lecturer Research Report, Funded by the Directorate General of Higher Education, 2007.

[9] J. C. Fernandes et al., "Anti-inflammatory cctivity of chitooligosaccharides in vivo," Marine Drugs, vol. 8, pp. 1763-1768, ISSN 1660-3397, March 2010

[10] Kaban, "Chemical modification of chitosan and application of products in organic chemistry," Ph.D. dissertation, Faculty of Science, University of North Sumatra, January 24, 2009.

[11] S.-B. Lin et al., "Preparation of antibacterial chito-oligosaccharide by altering the degree of deacetylation of $\beta$-chitosan in a Trichoderma harzianum chitinase-hydrolysing process," Journal of the Science of Food and Agriculture, vol. 89, no. 2, 30 January 2009, pp. 238-244.

[12] M. T. Liong and N. P. Shah, "Acid and bile tolerance and cholesterol removal ability of lactobacilli strains," Journal of Dairy Science vol. 88 pp. 55-66, 2005.

[13] M. T. Liong and N. P. Shah, "Bile salt deconjugation ability, bile salt hydrolase activity and cholesterol co-precipitation ability of lactobacilli strains," Int. Dairy Journal, vol. 15, pp. 391-398, 2005.

[14] M. T. Liong and N. P. Shah, "Optimization of growth of Lactobacillus casei ASCC 292 and production of organic acids in the presence of fructo oligosaccharide and maltodextrin," Journal Food Science, vol. 70, pp. M113-M120, 2005.

[15] M. T. Liong and N. P. Shah, "Optimization of cholesterol removal by probiotics in presence of prebiotics using response surface methodology," Applied. Environment Microbiolology, vol. 7, pp. $1745-175,2005$

[16] L. Wang et al., "Effects of chito-oligosaccharide supplementation on growth performance, nutrient Digestibility, intestinal morphology, and fecal shedding of Escherichia coli and Lactobacillus in weaning pigs," Journal of Animal Science, vol. 86, pp. 2609-2618, 2008.

[17] Mirzah, "Improving the Quality of Shrimp Waste Meal Nutritional Value Through Processing With Steam Heat," Research Journal of Andalas, vol. 26, pp. 7 -12, 1998.

[18] N. Kazami, S. Yasusato, M. Sakaguchi, and M. Kawakita, "Preparation of Chito-oligosaccharides by Two Step Hydrolysis," Chitin and Chitosan Research, vol. 11, no. 2, pp. 170-171, 2005.
[19] E. R. Nugraheni, S. S. Retno, and A. J. Umar, "Utilization of rice bran to increase the production of erythromycin from culture Saccharopolyspora erythraea ATCC 11635," Journal: Science and Sibernatika, vol. XVII, no. 3, 2004

[20] H. Puspita, "Synthesis of Chito-oligosaccharide (COS) from waste shrimp and crab as well as the Natural Resources Prebiotics Sinbiotik In vitro effects," Final Report of Student Creativity Research Program, Funded by the Directorate of Research and Community Services, the Directorate General of Higher Education Ministry of National Education in 2010

[21] E. Rochima, "Characterization of chitin and chitosan origin waste rajungan Cirebon in West Java," Article Publication Research, Faculty of IPB, 2005.

[22] P. Suptijah, H. Sumaryanto, S. Purwaningsih, and J. Santosa, "The effect of various methods of isolation of chitin and chitosan from shrimp shells to the levels and quality," The final report of research, Faperikan, IPB, Bogor, 1992

[23] Y. Wang et al., "Antimicrobial effect of Chito-oligosaccharides produced by chitosanase from Pseudomonas CUY8," Asia Pacific Journal of Clinical Nutrition, vol. 16, Suppl. 1 pp. 174-177, 2007.

[24] X. M. Feng et al., "Growth of lactic acid bacteria and Rhizopus oligosporus during barley tempeh fermentation," International Journal of Food Microbiology, vol. 104, issue 3, 25 October 2005, pp. 249-256.

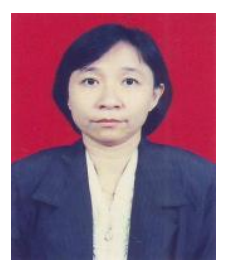

Agnes Sri Harti is a lecturer at Kusuma Husada Surakarta Institute of Health Science. She was born on August 9th, 1960 in Semarang Central of Java Indonesia. She as lecturer of course Basic Biology, Medical Biology, Biochemistry, Microbiology and Parasitology at the Diploma, S-1, D-IV Program of Nursing, Midwifery and Acupuncture. She has been post graduate S-1 Biology at Satya Wacana Christian University Salatiga in 1984 and Magister Program Biotechnology at the University of Gadjah Mada Yogyakarta in 2006.

Dra. Agnes Sri Harti, M.Si. She was researcher of grants of Higher Education Indonesia, Young Lecturer Research, Fundamental, the National Strategy and National Education Central Java Province. 